Check for updates

Cite this: RSC Adv., 2017, 7, 39739

Received 29th June 2017

Accepted 26th July 2017

DOI: $10.1039 / \mathrm{c} 7 \mathrm{ra} 07195 \mathrm{~g}$

rsc.li/rsc-advances

\section{Study on the preparation and performance of low gas permeability trifluoropropyl phenyl silicone rubber}

\begin{abstract}
Huaijun Zhu, (DD ${ }^{\text {ab }}$ Zilin Dai ${ }^{b}$ and Weiping Tu*a
In order to overcome the defects of opacity, high gas permeability, poor heat and solvent oil resistance of methyl silicone rubber, optically transparent trifluoropropyl phenyl silicone rubber was prepared by introducing trifluoropropyl and phenyl to organic silicone molecules. Then organic polysilazane (OPSZ) was coated on the trifluoropropyl phenyl silicone rubber surface with tetramethylhexamethylenediamine as a catalyst and a dense coating with low gas permeability was achieved. This process realized lowtemperature curing and siliceous transition. At the same time, optical performance, mechanical properties, oxygen permeation flux, and anti-sulfuration were measured. The results showed that the fluorine-containing phenyl silicone rubber had good optical transparency, tensile strength, elongation at break, tear strength, oil resistance and heat resistance. The OPSZ coating surface was continuous, uniform, dense and free of cracks and voids; meanwhile, the coating section was dense, uniform, seamless, without cracks. The interface between the coating and the silicone rubber exhibited good adhesion. Light transmission was over $92 \%$ between 400 and $800 \mathrm{~nm}$. When the coating thickness was more than $12 \mu \mathrm{m}$, the oxygen permeation flux remained unchanged, lamps had good anti-sulfuration ability, and luminous flux was maintained at over $99.8 \%$. when the mass fraction of tetramethyl hexamethylene diamine $(w)$ was over $5 \%$, siliceous transition was achieved under room temperature and $50 \%$ relative humidity for $24 \mathrm{~h}$.
\end{abstract}

\section{Introduction}

Silicone rubber can be used in packaging and sealing of precise electronic components, chips, LEDs, solar cells, fuel cells, medicine, etc. due to excellent properties of high-temperature resistance, radiation resistance, anti-UV, and anti-ageing. ${ }^{1-6}$ But low gas permeability is required, because permeable gases particularly, oxygen, hydrogen sulphide, and sulphur vapour can easily cause oxidation and sulfuration of electronic components, chips, electrodes, medicines, etc. and shorten their service lives.

Some researchers have achieved good results in improving the gas barrier by coating or depositing dense inorganic materials such as nano-silica on the rubber surface. ${ }^{7,8}$ Siliceous coating made from polysilazane has excellent gas barrier properties and has been widely used in electronic protection and chip packaging. Therein, perhydropolysilazane (PHPS) has high reactivity and can be hydrolyzed or oxidized to form SiON at low temperature, and the resulting coating is of high transparency, hardness, and density. But PHPS releases ammonia

${ }^{a}$ School of Chemistry and Chemical Engineering, South China University of Technology, Guangzhou 510640, China. E-mail: cewptu@scut.edu.cn

${ }^{b}$ Guangdong Research Institute of Rare Metals, Guangdong Academy of Sciences, Guangzhou 510651, China and hydrogen during curing, along with weight loss and changes in density. With increasing thickness, the volume change increases inner stress of the coating, resulting in crack formation on the coating. ${ }^{9-11}$

Organic polysilazane (OPSZ) easily forms a thick elastic coating due to the introduction of organic groups to molecular chains, increasing flexibility and reducing volume shrinkage, but conversion to a siliceous coating is very slow and requires baking at more than $300{ }^{\circ} \mathrm{C}$. Such high temperatures will inevitably lead to coated polymer oxidation, cracking and even carbonisation. Therefore, we wish to find a catalyst to realize low-temperature curing and siliceous transition and reduce gas permeability of the polymer.

Typically, silicone rubber is based on linear silicone oil and added silicone resin or silica as reinforcing fillers to improve mechanical properties. In order to obtain optically transparent silicone rubber, silicone resin with a refractive index matching that of silicone oil is needed. For silica reinforcement system, silicone oil with a refractive index matching that of silica is needed. Usually, silicone rubber cannot exhibit optical transparency due to differences in refractive index of silica and silicone oil, and hence, it cannot be applied to optical fields.

Phenyl silicone rubber has excellent heat resistance, but poor solvent resistance. Fluorine-containing silicone rubber has excellent solvent resistance but poor heat resistance. Fluorine- 
containing phenyl silicone rubber combines the advantages of phenyl silicone rubber and fluorine-containing silicone rubber, providing good tensile strength, elongation at break and tear strength, and at the same time, it has excellent oil resistance and heat resistance.

In this paper, optically transparent trifluoropropyl phenyl silicone rubber was prepared by introducing phenyl and trifluoropropyl to organic silicone molecules in order to overcome the defects of opacity, high gas permeability, no enduring high temperature and oil of methyl silicone rubber. OPSZ was coated on the silicone rubber surface with tetramethylhexamethylenediamine as a catalyst and a dense coating with low gas permeability was achieved. This process realized lowtemperature curing and siliceous transition. Optical performance, mechanical properties, oxygen permeation flux, and anti-sulfuration were measured in an attempt to resolve oxidation and sulfuration of electronic components, chips, electrodes, medicines, etc.

\section{Materials and methods}

\subsection{Materials}

Octaphenyl cyclotetrasiloxane (purity of 99.7\%) was purchased from Shaoguan Yueyouyan Chemical Technology Co. Ltd., China. Fluorine-containing hydroxy silicone oil (viscosity $=300$ $\mathrm{mPa}$ s, volatility $<0.5 \%$ ) was purchased from Weihai Xinyuan Chemical Co. Ltd., China. Vinyl-terminated silicone oil (viscosity $=1000 \mathrm{mPa} \mathrm{s}$, volatility $<0.5 \%$ ) was purchased from Jiangxi Xinghuo Chemical Factory, China. Dimethyl silicone oil (volatility $<0.5 \%$ ), high-hydro silicone oil (hydrogen content of $1.58 \%$, volatility $<0.5 \%$ ) and hydrophobic fumed silica (HDK H20) were purchased from Wacker Chemical Co. Ltd., China. Nitrogen and ammonia (content $>99 \%$ ) were purchased from Guangzhou Shiyuan Gas Co., Ltd., China. Chemically pure tetramethylhexamethylenediamine, tetramethylethylenediamine, hexamethylenediamine, $m$-xylylenediamine, and trimethylenebis ( $N$-methylpyridine) were purchased from Aladdin Industrial Co., China. Platinum catalyst (platinum content of 5000 ppm) was purchased from Shanghai Heraeus Industrial Technology Materials Co., Ltd., China. Chemically pure dibutyl ether and pyridine were purchased from Sun Chemical Technology Co., Ltd., China. Methyl vinyl MQ silicone resin (vinyl content of $1.5 \%$, viscosity of $8000 \mathrm{mPa}$ s, refractive index of 1.41 , volatility < $0.3 \%$ ); methyl hydrogen silicone oil (hydrogen content of $0.8 \%$, viscosity of $80 \mathrm{mPa} \mathrm{s}$, refractive index of 1.41 , volatility $<0.3 \%$ ); and vinyl silicone oil (vinyl content of $0.135 \%$, viscosity of $10000 \mathrm{mPa} \mathrm{s}$, refractive index of 1.41 , volatility $<0.1 \%$ ) were synthesized by us. Other reagents were chemically pure grade.

\subsection{Methods}

\subsubsection{Synthesis}

Synthesis of fluorine-containing phenyl hydrogen silicone oil. The following substances were added to a $2 \mathrm{~L}$ three-necked flask: $150 \mathrm{~g}$ methyl silicone oil with viscosity of $5 \mathrm{mPa} \mathrm{s}, 250 \mathrm{~g}$ octaphenyl cyclotetrasiloxane, and $100 \mathrm{~g}$ fluorine-containing hydroxy silicone oil. The mixture was stirred until uniform, and then $0.5 \mathrm{~g}$ potassium hydroxide was added. The flask was heated to $160{ }^{\circ} \mathrm{C}$ for 7 hours and then cooled to room temperature. Into the flask, $50 \mathrm{~g}$ sulphuric acid (content of 98\%), $800 \mathrm{~g}$ methylcyclohexane and $500 \mathrm{~g}$ methyl hydrogen silicone oil were added and stirred at room temperature for 5 hours; then $200 \mathrm{~g}$ sodium carbonate was added to neutralise the sulphuric acid until $\mathrm{pH}=7$. The mixture was vacuum filtered and the solvent was removed to yield a colourless and transparent fluorinecontaining phenyl hydrogen silicone oil, with hydrogen content of $0.78 \%$, refractive index of 1.4605 , viscosity of 425 $\mathrm{mPa}$ s (labelled as FBH-1).

By adjusting the ratio of raw materials, fluorine-containing phenyl hydrogen silicone oil with refractive indexes of 1.42 , $1.44,1.48$ and 1.50 were obtained (labelled as FBH-2, FBH-3, FBH-4, and FBH-5, respectively).

Synthesis of fluorine-containing phenyl vinyl silicone oil. The following substances were added to a $2 \mathrm{~L}$ three-necked flask: $200 \mathrm{~g}$ vinyl silicone oil with viscosity of $1000 \mathrm{mPa} \mathrm{s}, 500 \mathrm{~g}$ octaphenyl cyclotetrasiloxane and $300 \mathrm{~g}$ fluorine-containing hydroxy silicone oil. The mixture was stirred until uniform, and then $0.8 \mathrm{~g}$ lithium hydroxide was added. The flask was heated to $160{ }^{\circ} \mathrm{C}$ for 7 hours and then cooled to room temperature. Into the flask, $800 \mathrm{~g}$ methylcyclohexane and $1.1 \mathrm{~g}$ acetic acid were added and stirred for 1 hour; then $2.2 \mathrm{~g}$ sodium bicarbonate was added to neutralise the excessive acetic acid. The mixture was vacuum filtered and the solvent was removed to yield a colourless and transparent fluorine-containing phenyl vinyl silicone oil, with the refractive index of 1.4602, viscosity of $12240 \mathrm{mPa}$ s (labelled as FBV-1).

By adjusting the ratio of raw materials, fluorine-containing phenyl vinyl silicone oil with refractive indexes of 1.42, 1.44, 1.48, and 1.50, were obtained (labelled as FBV-2, FBV-3, FBV-4, and FBV-5, respectively).

Preparation of fluorine-containing phenyl silicone rubber films. About 100 parts of the fluorine-containing phenyl vinyl silicone oil and 40 parts of hydrophobic fumed silica were added into a kneader, and kneaded at $140{ }^{\circ} \mathrm{C}$ and $0.08 \mathrm{MPa}$ for 4 hours. Then the mixture was cooled and packaged. Some amounts of the mixture, fluorine-containing phenyl vinyl silicone oil, and fluorine-containing phenyl hydrogen silicone oil, platinum catalyst were taken together and stirred until uniform. This mixture was then poured into molds $(10 \mathrm{~cm} \times 4 \mathrm{~cm} \times 2 \mathrm{~mm})$ and vacuum deaerated until there were no residual air bubbles. Finally, the molds were placed in an oven and baked at $100{ }^{\circ} \mathrm{C}$ for 2 hours and at $150{ }^{\circ} \mathrm{C}$ for 3 hours sequentially, and then cooled to room temperature to give films of trifluoropropyl phenyl silicone rubber with hardness of $70 \mathrm{~A}$.

Preparation of methyl silicone rubber films. Methyl vinyl MQ silicone resin, methyl hydrogen silicone oil, vinyl silicone oil, and platinum catalyst were mixed in proportion and stirred until uniform. These mixtures were then poured into molds $(10 \mathrm{~cm} \times 4 \mathrm{~cm} \times 2 \mathrm{~mm})$, and vacuum deaerated until there were no residual air bubbles. Finally, the molds were placed in an oven and baked at $100{ }^{\circ} \mathrm{C}$ for 2 hours and $150{ }^{\circ} \mathrm{C}$ for 3 hours, and then cooled to room temperature to give cured methyl silicone rubber films with a hardness of $70 \mathrm{~A}$.

Preparation of packaged LED lamps. Trifluoropropyl phenyl silicone rubbers were packaged on 5050 chips. Then, they were 
placed in an oven and baked at $100{ }^{\circ} \mathrm{C}$ for 2 hours and $150{ }^{\circ} \mathrm{C}$ for 3 hours, and then cooled to room temperature to give packaged LED lamps.

Preparation of OPSZ. A 1 litre four-necked flask fixed with an intake duct, mechanical stirrer and condenser was used as reactor. Nitrogen, $200 \mathrm{~mL}$ of pyridine, and $28.75 \mathrm{~g}$ of methylhydrogen dichlorosilane were added to the four-necked flask, and then $20 \mathrm{~g}$ of ammonia gas was slowly pumped in. The mixture reacted in an ice-water bath for 4 hours, and then dry nitrogen was pumped into the flask for 30 minutes to remove excess ammonia. The mixture was vacuum filtered and the solvent was removed under $-0.098 \mathrm{MPa}$ and $180{ }^{\circ} \mathrm{C}$ to yield $13.86 \mathrm{~g}$ of colorless transparent OPSZ, the yield being $93.96 \%$.

Preparation of OPSZ solution. Under dry nitrogen, $80 \mathrm{~g}$ dibutyl ether and $20 \mathrm{~g}$ OPSZ were added to a $100 \mathrm{~mL}$ three-necked flask and stirred with a stirrer; then $1 \mathrm{~g}$ of tetramethylhexamethylenediamine was added, stirring for $1 \mathrm{~h}$. A colorless, transparent OPSZ solution was obtained.

Preparation of OPSZ coatings. OPSZ solution was brushed onto the silicone rubber films and the packaged LED lamps surface, with single or multiple brushing as needed. OPSZ would convert into a siliceous coating after curing at room temperature with $50 \%$ relative humidity for 24 hours.

2.2.2 Spectroscopic characterization. An infrared spectroscope (Model Nicolet 5700, by Thermo Electron Corporation, America. Resolution: $4 \mathrm{~cm}^{-1}$; number of scans: 32), SEM (Model Hitachi-S3700N, by Hitachi, Japan. Resolution: $3 \mathrm{~nm}$ ), drying oven (Model DK-136A, by Dongguan Haobang Industrial Equipment Co. Ltd., China), solid-crystal microscope (Model XTJ-2600, by Shenzhen Osiwei Optical Instrument Co. Ltd., China), dispenser (Model Musashi Shotmimisl, by Shenzhen Lingdian High-tech Co. Ltd., China), and oxygen permeability tester (Model STO-1000A, by Guangzhou Xitang Electrical Technology Co. Ltd., China) were used.

2.2.3 Oxygen permeation flux. Silicone rubber films of $10 \mathrm{~cm} \times 10 \mathrm{~cm} \times 1 \mathrm{~mm}$ were prepared. The OPSZ solution was brushed onto the silicone rubber films and cured. The tests were carried out according to ASTM D 3985 "Standard Test of Oxygen Permeability". The sample size was around $50 \mathrm{~cm}^{2}$.

2.2.4 Sulfuration resistance. We placed $10 \mathrm{~g}$ of sublimed sulphur into a $1000 \mathrm{~mL}$ beaker, and placed them in 10 lamps. The beaker was sealed and placed into an oven at $100{ }^{\circ} \mathrm{C}$ and heated for 24 hours. To measure sulfuration resistance of the rubber, we measured the optical power of the lamps before and after sulfuration.

\section{Results and discussion}

\subsection{Structure analysis}

Because of the large deviation in refractive index among methyl silicone oil, octaphenyl cyclotetrasiloxane and fluorinecontaining hydroxy silicone oil, they formed an opaque mixture when they were mixed directly. A colourless and transparent product was obtained because breaking and rearrangement of molecular chains improve homogeneity of phase. Thus, we can judge whether the raw materials reacted by transparency (see Fig. 1 below).

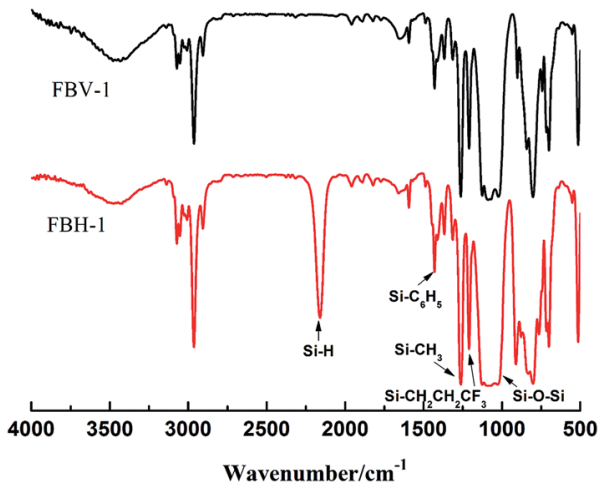

Fig. 1 FT-IR spectra of FBH-1 and FBV-1.

As can be seen in Fig. 1, $1431 \mathrm{~cm}^{-1}$ and $1080 \mathrm{~cm}^{-1}$ were the characteristic peaks of $\mathrm{Si}-\mathrm{C}_{6} \mathrm{H}_{5}, 1255 \mathrm{~cm}^{-1}$ was the characteristic peak of $\mathrm{Si}-\mathrm{CH}_{3}, 1210 \mathrm{~cm}^{-1}$ was the characteristic peak of $\mathrm{Si}-\mathrm{CH}_{2} \mathrm{CH}_{2} \mathrm{CF}_{3}, 1085 \mathrm{~cm}^{-1}$ was the characteristic peak of Si-O$\mathrm{Si}, 2135 \mathrm{~cm}^{-1}$ was the characteristic peak of $\mathrm{Si}-\mathrm{H}$, and the characteristic peak of $\mathrm{Si}-\mathrm{Vi}$ was not obvious due to the presence of phenyl, indicating that the products obtained in this study were fluorine-containing phenyl hydrogen silicone oil and fluorine-containing phenyl vinyl silicone oil.

\subsection{Optical properties of fluorine-containing phenyl silicone rubber}

Methyl silicone rubbers reinforced by fumed silica were not optically transparent due to the deviation in refractive index between methyl silicone oil and fumed silica. If the refractive index of silicone oil was similar or identical to fumed silica, we could obtain an optically transparent silicone rubber. The introduction of phenyl can increase the refractive index of silicone oil and trifluoropropyl can reduce the refractive index. By adjusting the ratio of phenyl and trifluoropropyl, we can obtain specific content and refractive index of fluorine-containing phenyl silicone oil.

Fig. 2 shows the transmittance of the fluorine-containing phenyl silicone rubber prepared by different refractive indexes of silicone oil and fumed silica at $450 \mathrm{~nm}$, m (fumed silica) $/ \mathrm{m}$ (silicone oil) $=30: 70$, thickness $2 \mathrm{~mm}$.

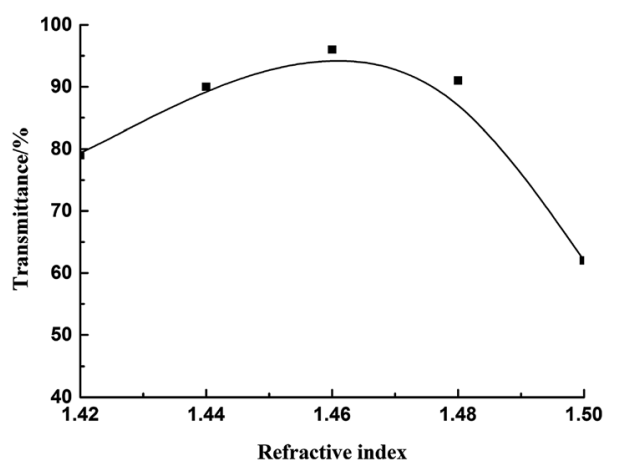

Fig. 2 Transmittance of the fluorine-containing phenyl silicone rubber prepared by different refractive indexes of silicone oil and fumed silica at $450 \mathrm{~nm}$. 


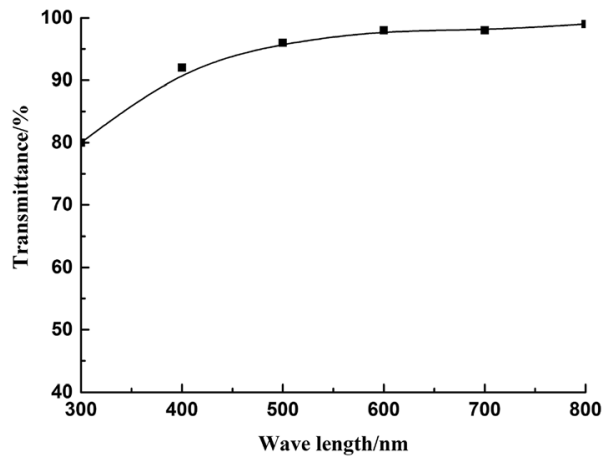

Fig. 3 Transmittance of rubber with a refractive index of 1.46 at different wavelengths.

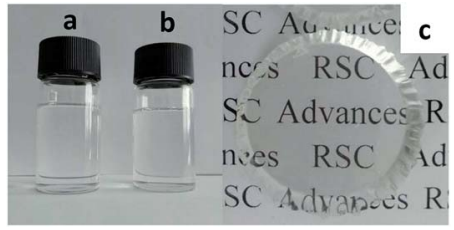

Fig. 4 Pictures of silicone oils ( $a$ and b) and cured rubber (c). (a) Fluorine-containing phenyl vinyl silicone oil, (b) fluorine-containing phenyl hydrogen silicone oil, (c) fluorine-containing phenyl silicone rubber.

As can be seen in Fig. 2, when the refractive index of the fluorine-containing phenyl silicone oil was $1.46 \pm 0.01$, the transmittance was over $92 \%$, and the rubber obtained was optically transparent. When the refractive index of the silicone oil was 1.46 , the transmittance was the highest, up to $96 \%$. Therefore, it is necessary to select silicone oil with refractive index of 1.46 to get the best transmittance.

A heterogeneous phase was formed when the refractive index of silicone oil did not match that of fumed silica. When light beam was passed through the rubber, part of the beam deviated from the original direction of spread due to scattering, and the rubber appeared opaque. When the refractive indexes of both were similar or identical, the beam was considered to spread in homogeneous media, and the scattering was too weak to observe, and the rubber appeared transparent.

Fig. 3 shows the transmittance of fluorine-containing phenyl silicone rubber with a refractive index of 1.46 at different wavelengths.
As seen in Fig. 3, at $300 \mathrm{~nm}$, the transmittance was $80 \%$, and at the visible wavelength of $400-800 \mathrm{~nm}$, the transmittance was over $92 \%$. The result showed that the rubber films had good transmittance at visible wavelength. The pictures of silicone oils and cured rubber are shown in Fig. 4.

\subsection{Mechanical properties}

Samples were prepared according to Method 1.3.3; the ratio of $n\left(\mathrm{Si}-\mathrm{CH}=\mathrm{CH}_{2}\right) / n(\mathrm{Si}-\mathrm{H})$ was controlled at $1: 1.1,1: 1.2,1: 1.3$, $1: 1.4$, and $1: 1.5$ (labelled as R1, R2, R3, R4, and R5, respectively). The mechanical performance test results are shown in Table 1.

As can be seen in Table 1, the cured fluorine-containing phenyl silicone rubber was of the tensile strength $>5.3 \mathrm{MPa}$, elongation at break $>340 \%$, and tear strength $>22 \mathrm{kN} \mathrm{m}^{-1}$ at $25^{\circ} \mathrm{C}$, with excellent performance. After immersion in $\mathrm{C}$ oil at $25^{\circ} \mathrm{C}$ for 72 hours, the largest volume change was of $7.75 \%$ and mass change of $6.68 \%$, with good oil resistance. After hightemperature ageing at $280{ }^{\circ} \mathrm{C}$ for 1000 hours, we obtained tensile strength $>4.0 \mathrm{MPa}$, elongation at break $>210 \%$, and tear strength $>17 \mathrm{kN} \mathrm{m}^{-1}$, with good heat resistance.

\subsection{Curing mechanism of OPSZ}

Chemical structure of OPSZ is as below.

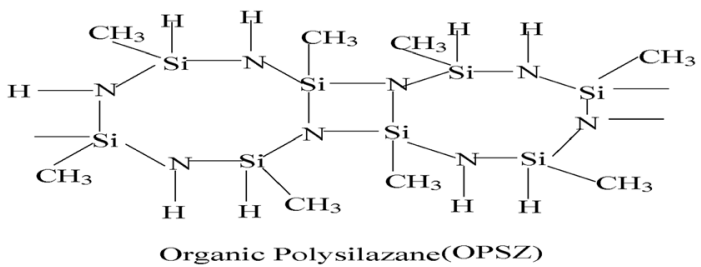

Curing mechanism of OPSZ is as below.

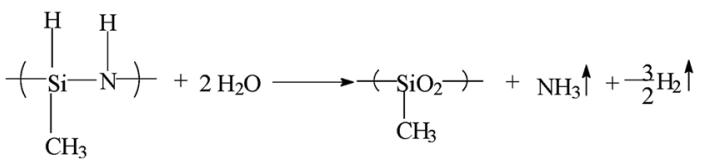

In the chemical structure of OPSZ, the electronegativity of $\mathrm{Si}$ and $\mathrm{N}$ atoms have a difference of 1.2 , and the $\mathrm{Si}-\mathrm{N}$ bond is between the $\mathrm{Si}-\mathrm{C}$ and $\mathrm{Si}-\mathrm{O}$ bonds, similar to the $\mathrm{Si}-\mathrm{Cl}$ bond, so the $\mathrm{Si}-\mathrm{N}$ bond has ionic bond characteristics. OPSZ forms a quadrilateral structure in the molecular centre, and the

Table 1 Performance tests of fluorine-containing phenyl silicone rubber

\begin{tabular}{|c|c|c|c|c|c|c|}
\hline Samples & Standard & R1 & $\mathrm{R} 2$ & R3 & R4 & R5 \\
\hline Hardness $\left(25^{\circ} \mathrm{C}\right)$ & GB/T531.1-2008 & $65 \mathrm{~A}$ & $68 \mathrm{~A}$ & $70 \mathrm{~A}$ & $72 \mathrm{~A}$ & $73 \mathrm{~A}$ \\
\hline Tensile strength $\left(25^{\circ} \mathrm{C}\right), \mathrm{MPa}$ & GB/T528-2009 & 5.4 & 5.3 & 5.5 & 6.5 & 6.8 \\
\hline Tensile strength $\left(280^{\circ} \mathrm{C} \times 1000 \mathrm{~h}\right), \mathrm{MPa}$ & GB/T528-2009 & 4.0 & 4.0 & 4.2 & 4.1 & 4.3 \\
\hline Elongation at break $\left(25^{\circ} \mathrm{C}\right), \%$ & GB/T528-2009 & 350 & 390 & 420 & 380 & 340 \\
\hline Elongation at break $\left(280^{\circ} \mathrm{C} \times 1000 \mathrm{~h}\right), \%$ & GB/T528-2009 & 240 & 230 & 220 & 220 & 210 \\
\hline Tear strength $\left(25^{\circ} \mathrm{C}\right), \mathrm{kN} \mathrm{m}^{-1}$ & GB/T529-1999 & 22 & 24 & 23 & 24 & 26 \\
\hline Tear strength $\left(280^{\circ} \mathrm{C} \times 1000 \mathrm{~h}\right), \mathrm{kN} \mathrm{m}^{-1}$ & GB/T529-1999 & 18 & 19 & 17 & 18 & 21 \\
\hline Oil resistance, $\mathrm{C}$ oil, $\Delta m / \%\left(25^{\circ} \mathrm{C} \times 72 \mathrm{~h}\right)$ & GB/T1690-2009 & 6.68 & 6.43 & 6.35 & 6.48 & 6.64 \\
\hline Oil resistance, $\mathrm{C}$ oil, $\Delta v / \%\left(25^{\circ} \mathrm{C} \times 72 \mathrm{~h}\right)$ & GB/T1690-2009 & 7.23 & 7.62 & 7.68 & 7.53 & 7.75 \\
\hline
\end{tabular}




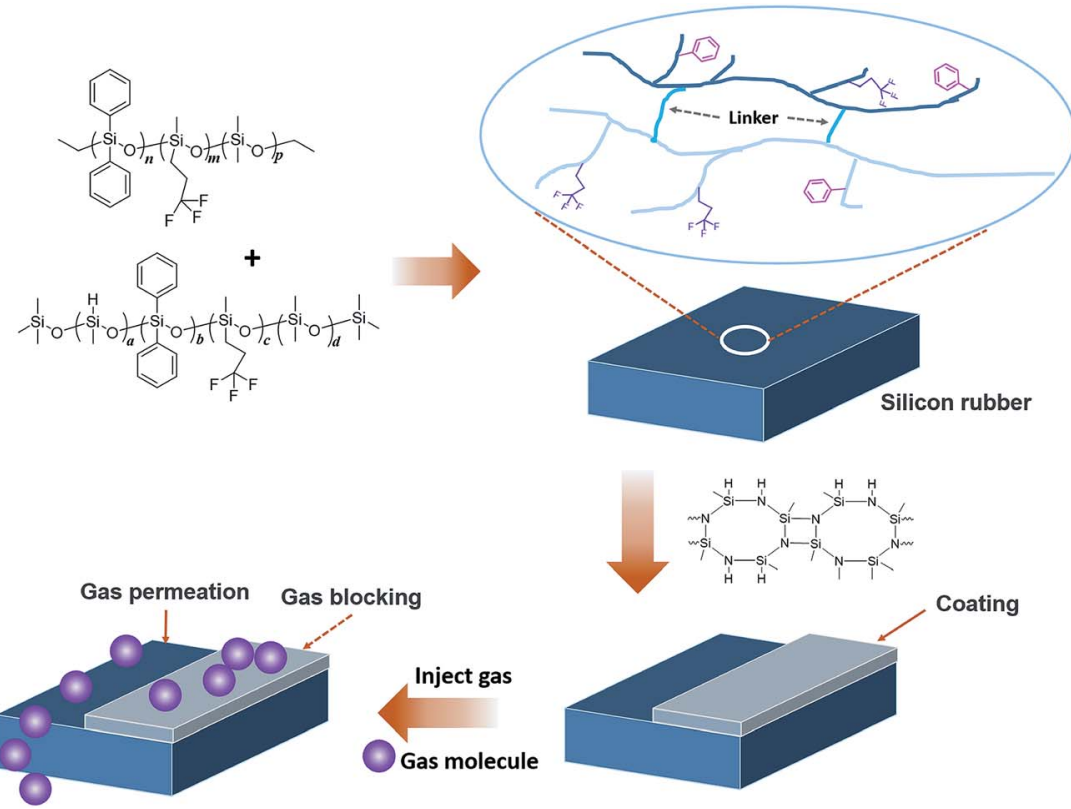

Fig. 5 Sketch map of cured silicone rubber and low gas permeability coating.

structure is unstable because of large tension; therefore, the Si$\mathrm{N}$ bond is readily converted to other bonds.

Fig. 5 shows the sketch map of cured silicone rubber and low gas permeability coating.

\subsection{Structure characterisation}

Fig. 6 shows the infrared spectra of OPSZ before Fig. 6(a) and after Fig. 6(b) curing; $3400 \mathrm{~cm}^{-1}$ and $1180 \mathrm{~cm}^{-1}$ were the characteristic peak of $\mathrm{N}-\mathrm{H}, 2160 \mathrm{~cm}^{-1}, 1261 \mathrm{~cm}^{-1}, 820-1020$ $\mathrm{cm}^{-1}$ were the characteristic peaks of $\mathrm{Si}-\mathrm{H}, \mathrm{Si}-\mathrm{CH}_{3}$, and $\mathrm{Si}-\mathrm{N}$, respectively. All confirmed that the product contained $\mathrm{Si}-\mathrm{H}, \mathrm{Si}-$ $\mathrm{CH}_{3}, \mathrm{~N}-\mathrm{H}$ and $\mathrm{Si}-\mathrm{N}$ bonds.

Fig. 6(b) shows the infrared spectrum of OPSZ after curing. As can be seen, the characteristic peaks of the $\mathrm{N}-\mathrm{H}$ bond at 3400 $\mathrm{cm}^{-1}$ and at $1180 \mathrm{~cm}^{-1}$ were reduced and the characteristic peak of Si-H bond at $2160 \mathrm{~cm}^{-1}$ and that of $\mathrm{Si}-\mathrm{N}-\mathrm{Si}$ bond at

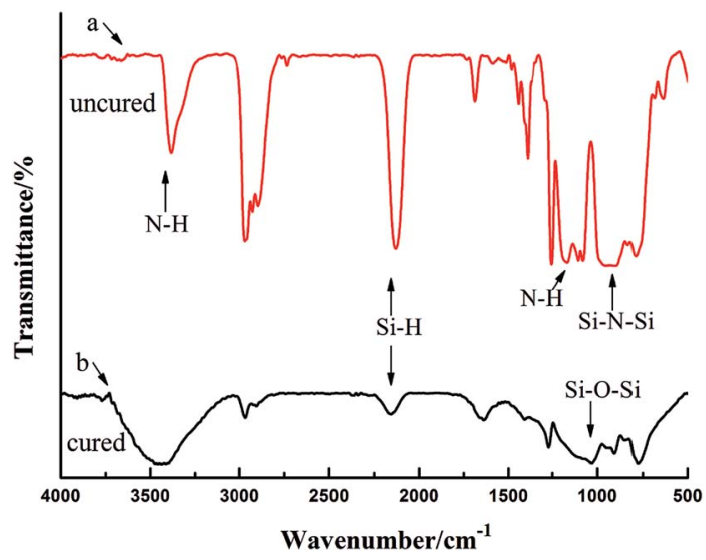

Fig. 6 Infrared spectra of OPSZ before (a) and after (b) curing.
820-1020 $\mathrm{cm}^{-1}$ decreased significantly, with the formation of a new characteristic peak of $\mathrm{Si}-\mathrm{O}-\mathrm{Si}$ bond at $1080 \mathrm{~cm}^{-1}$, thus indicating that the $\mathrm{Si}-\mathrm{H}$ and $\mathrm{Si}-\mathrm{N}$ bonds had converted to $\mathrm{Si}-\mathrm{O}$ bonds.

\subsection{Surface and section appearance of coating}

Surface and section appearance of coatings were characterised by SEM (see Fig. 7 below).

Photograph Fig. 7(a) is the surface appearance of coating, and as can be seen, the coating surface was continuous, uniform, dense, crack-free and void. Photographs Fig. 7(b) to (f) are section appearances of coatings; Fig. 7(b) to (e) show that the thickness of the coating increased, but the coatings were still dense, seamless and crack-free, indicating that the coating had excellent adhesion to silicone rubber. But with increasing thickness of the coating, as in Fig. 7(f), there was a clear crack between the silicone rubber and coating, indicating that the adhesion between the coating and silicone rubber deteriorated. OPSZ released ammonia and hydrogen during curing, along with weight loss and changes in density. With increasing thickness, the volume change increased the inner stress of the coating, resulting in the coating becoming cracked. The experiments found that the interface between the coating and silicone rubber exhibited good adhesion when the coating thickness was less than $32-35 \mu \mathrm{m}$.

Generally, PHPS coating has a thickness from tens to hundreds of nanometers; when the coating thickness exceeds 1-2 $\mu \mathrm{m}$, coating cracks due to volume contraction. ${ }^{8}$ PHPS coating is of high hardness and rigidity, and can only be coated on a hard substrate surface. Any polymer surface having slight elasticity cannot be coated, because a polymer is easily deformed and the coatings are easily crack and peel. In contrast, OPSZ coating has flexibility due to the introduction of methyl 

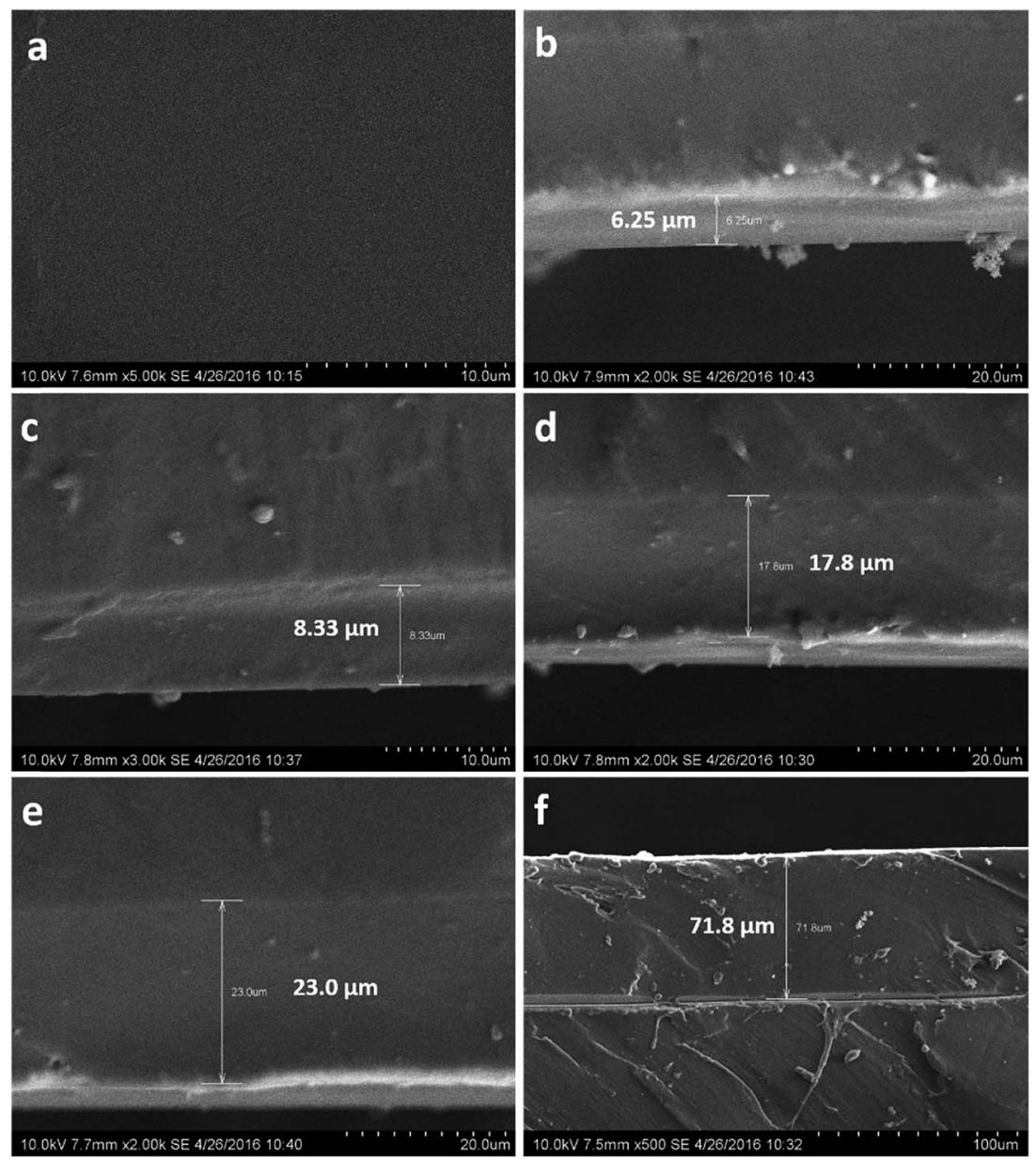

Fig. 7 Surface (a) and section (b-f) morphology of coatings.

Table 2 Tests of oxygen permeation flux

\begin{tabular}{lll}
\hline Samples & $\begin{array}{l}\text { Coating } \\
\text { thickness/ } \mu \mathrm{m}\end{array}$ & $\begin{array}{l}\text { Oxygen permeation flux/ } \\
\mathrm{cm}^{3} \mathrm{~m}^{2}, 24 \mathrm{~h} 0.1 \mathrm{MPa}\end{array}$ \\
\hline $\begin{array}{l}\text { Before coating } \\
\text { (methyl silicone rubber) }\end{array}$ & 0 & 12500 \\
$\begin{array}{l}\text { After coating } \\
\text { (methyl silicone rubber) }\end{array}$ & 12.1 & 1.4 \\
$\begin{array}{l}\text { Before coating } \\
\text { (trifluoropropyl phenyl } \\
\text { silicone rubber) }\end{array}$ & 0 & 280 \\
$\begin{array}{l}\text { After coating } \\
\text { (trifluoropropyl phenyl } \\
\text { silicone rubber) }\end{array}$ & 12.4 & 1.3 \\
\end{tabular}

and is not brittle when a slight deformation occurs, thus maintaining good adhesion. However, due to the introduction of a methyl group, the density of an OPSZ coating is lower than a PHPS coating. For the same coating thickness, the gas barrier property of OPSZ coating is inferior to that of PHPS coating, but we can increase thickness to overcome this. With increasing thickness, gas permeability and diffusion paths in the coating increases and the ability of gas to permeate and diffuse is decreases.

\subsection{Oxygen permeation flux}

The tests were carried out according to 2.2.3. Table 2 displays the test results.

Table 2 shows that before coating, methyl silicone rubber had the maximum oxygen permeation flux. This was because the molecular chains of methyl silicone rubber were spiral, the side chains of methyl were relatively isolated, and the intermolecular forces were so weak that molecular chains could rotate easily and oxygen could freely permeate. For fluorine-containing phenyl silicone rubber, the interaction forces increased because phenyl has a larger molecule structure and trifluoropropyl contains a longer carbon chain, which can twine and overlap. A highelectron-density barrier layer was formed around the molecular chains, especially the fluorine atom, which has a very small radius, filling the voids in the molecule, so that the barrier layer became denser and stopped oxygen molecules from freely permeating among the molecular chains, resulting in decreased oxygen permeation flux; hence, gas permeability was lower than methyl silicone rubber.

After coating, methyl silicone rubber exhibited good gas barrier properties, and the oxygen permeation flux reduced to $0.0112 \%$ of that before coating. For fluorine-containing phenyl silicone rubber after coating, the oxygen permeation flux 


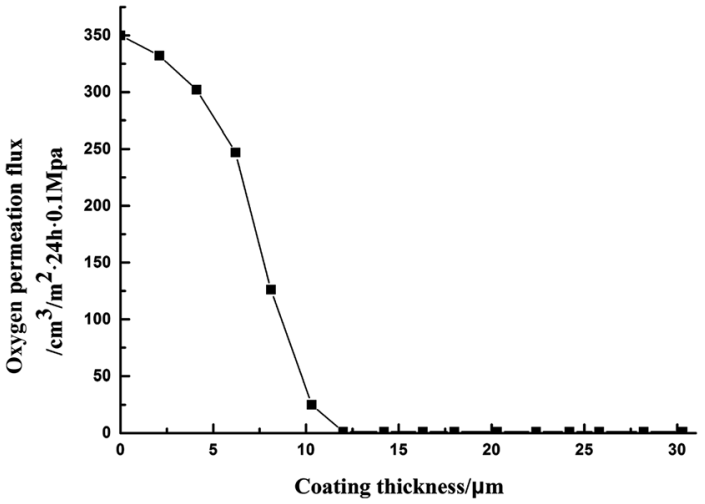

Fig. 8 Influence of coating thickness on oxygen permeation flux.

reduced to $0.4643 \%$ of that before coating. Although values of oxygen permeation flux had a ratio of 44.64 between fluorinecontaining phenyl silicone rubber and methyl silicone rubber, they had the same oxygen permeation flux after coating. So, we conclude that a gas barrier occurs in the OPSZ coating, but is not related to the gas permeability of the substrate.

The cured OPSZ formed a carbonaceous Si-O layer on the surface of silicone rubber, with excellent density, and oxygen was impermeable to the inorganic layer and the gas barrier improved, thus exhibiting an excellent gas barrier effect.

In actual use, we found considerable influence of coating thickness on oxygen permeation flux, although the coating was too thin to reduce cracks, voids and other defects, especially for complex shapes. Due to surface roughness of the substrate, it was difficult for the coating to obtain complete coverage and the penetration and diffusion of oxygen in the coating were of shorter distances, causing a poor barrier effect. Only when the coating reached a certain thickness was oxygen blocked, preventing continued penetration and diffusion due to the obstruction of inorganic material particles, leading to excellent barrier properties. Fig. 8 shows the effect of coating thickness on oxygen permeation flux.

As can be seen, with increasing thickness of the coating, oxygen permeation flux decreased. With coating thickness of 12 $\mu \mathrm{m}$ or more, oxygen permeation flux remained unchanged, and after that, increasing the coating thickness had no effect on oxygen permeation flux. When the thickness was in the range 32-35 $\mu \mathrm{m}$, volume changes increased internal stress of the coating, resulting in the coating becoming cracked. Therefore, the coating thickness should be controlled at 15-20 $\mu \mathrm{m}$.

\subsection{Sulfuration resistance}

The tests were carried out according to 2.2.4. The results of the lamps photoelectronic test before and after sulfuration are shown in Table 3.

As can be seen from Table 3, for lamps packaged by methyl silicone rubber before coating, the luminous flux maintenance was $65.21 \%$ after sulfuration. For lamps packaged by fluorinecontaining phenyl silicone rubber before coating, the luminous flux maintenance was $\mathbf{9 3 . 5 4 \%}$ after sulfuration. Lamps packaged by fluorine-containing phenyl silicone rubber after coating had good anti-sulfuration ability, and the luminous flux maintenance was over $99.9 \%$ after sulfuration.

This is because the cured OPSZ could form a carbonaceous $\mathrm{Si}-\mathrm{O}$ layer on the surface of silicone rubber, with excellent density, and because sulfuric vapour was impermeable to the inorganic layer; thus, the gas barrier was improved and an excellent gas barrier effect was observed.

\subsection{Influence of amine catalyst}

OPSZ curing can be divided into three stages: (1) the coating became touch dry because of solvent evaporation and selfcrosslinking characteristics of OPSZ; (2) the coating and moisture reacted, releasing hydrogen and ammonia and increasing density; and (3) there was no substantial loss of quality in forming a stable structure.

The transition of OPSZ to a siliceous material is very slow because of steric hindrance of methyl at room temperature, taking OPSZ more than 24 hours to become touch dry and three weeks to form a stable structure. In order to improve curing speed, we can take a variety of curing forms, such as using an ammonia atmosphere, ${ }^{12,13}$ exposure to hydrogen peroxide vapor, ${ }^{14}$ hydrothermal treatment, ${ }^{15}$ using a noble metal catalyst ${ }^{16}$ or amine catalyst, ${ }^{17}$ and vacuum ultraviolet light irradiation. ${ }^{\mathbf{1 8 , 1 9}}$ Typically, with catalystfree, high-temperature baking is required to achieve siliceous conversion, such as $450{ }^{\circ} \mathrm{C}$ baking for 1 to 2 hours; with the use of a palladium catalyst, siliceous conversion requires $250{ }^{\circ} \mathrm{C}$ baking

Table 3 Photoelectronic test of lamps before and after sulfuration

\begin{tabular}{|c|c|c|c|c|}
\hline Package silicone rubber & $\begin{array}{l}\text { Coating } \\
\text { thickness } / \mu \mathrm{m}\end{array}$ & $\begin{array}{l}\text { Average optical power } \\
\text { before sulfuration } / 10^{-2} \mathrm{~W}\end{array}$ & $\begin{array}{l}\text { Average optical power } \\
\text { after sulfuration } / 10^{-2} \mathrm{~W}\end{array}$ & $\begin{array}{l}\text { Average flux maintenance } \\
\text { rate after sulfuration/\% }\end{array}$ \\
\hline $\begin{array}{l}\text { Before coating (methyl } \\
\text { silicone rubber) }\end{array}$ & 0 & 2.142 & 1.400 & 65.21 \\
\hline $\begin{array}{l}\text { After coating (methyl } \\
\text { silicone rubber) }\end{array}$ & 17.2 & 2.132 & 2.130 & 99.91 \\
\hline $\begin{array}{l}\text { Before coating (fluorine- } \\
\text { containing phenyl silicone } \\
\text { rubber) }\end{array}$ & 0 & 2.413 & 2.257 & 93.54 \\
\hline After coating (fluorine- & 17.8 & 2.404 & 2.402 & 99.92 \\
\hline
\end{tabular}

containing phenyl silicone rubber) 
Table 4 Amine compounds

\begin{tabular}{llllll}
\hline Number & I & II & III & IV & V \\
\hline $\begin{array}{l}\text { Amine } \\
\text { compounds }\end{array}$ & $\begin{array}{l}\text { Tetramethylhexamethy- } \\
\text { lenediamine }\end{array}$ & $\begin{array}{l}\text { Tetramethylethy- } \\
\text { lenediamine }\end{array}$ & $\begin{array}{l}m \text {-Xylylene- } \\
\text { diamine }\end{array}$ & $\begin{array}{l}\text { Hexamethy- } \\
\text { lenediamine }\end{array}$ & $\begin{array}{l}\text { Trimethylenebis } \\
(N \text {-methylpyridine })\end{array}$
\end{tabular}

for 2 to 4 hours; and with an amine catalyst, siliceous conversion requires $100{ }^{\circ} \mathrm{C}$ baking for 24 to 72 hours. For this study, an ammonia atmosphere, heat treatment, palladium catalysis, and ultraviolet radiation are not suitable, all of which can cause damage to the chips or silicone rubber, so it is necessary to find a suitable amine catalyst in order to accelerate siliceous conversion at low temperature.

Different coating solutions were prepared by changing the type and amount of solvent and amine compounds. The tests were carried out according to 2.2.3. The degree of conversion of coating was evaluated by oxygen permeation flux. Tables 4 and 5 display the amine compounds and test results, respectively.

As can be seen, the amine compounds used in test no. 6, 8, and 10 were of too low solubility in dibutyl ether to prepare a uniform, continuous coating.

At the same dosage and curing conditions, using tetramethylethylenediamine, $m$-xylylenediamine, hexamethylenediamine, or trimethylenebis ( $N$-methylpyridine) as catalysts, the oxygen permeation flux was higher than tetramethylhexanediamine. We could not obtain high siliceous conversion and highdensity coatings at low temperature in this way.

Even using a lower amount of tetramethylhexamethylenediamine as catalyst, the oxygen permeation flux did not increase. But with an increased amount, the oxygen permeation flux significantly reduced. When $w$ (amine compounds) $>5 \%$, the oxygen permeation flux remained unchanged, so the optimum amount of tetramethylhexamethylenediamine was $5 \%$.

The molecular structure of tetramethylhexamethylenediamine consists of six $\mathrm{CH}_{2}$ connecting two $\mathrm{N}$ atoms, one at each end, and from the electronic and stereochemical point of view, it has a small electron density and steric hindrance, so it reacts easily with Si-N bonds. Since an $\mathrm{N}$ atom attaches to a hydrocarbon group, compatibility is improved and the electron-donating ability is enhanced. At the same time, the number of carbon atoms in a hydrocarbon group linking $\mathrm{N}$ atoms must be limited for electron density and steric reasons, because too much or too little may hinder their interaction. For example, tetramethylethylenediamine and tetramethylhexanediamine, although structurally similar, have significantly different catalytic effects. $m$-Xylylenediamine, hexamethylenediamine, and trimethylenebis ( $N$-methylpyridine) do not have a similar structure and are not as effective as tetramethylhexanediamine at low temperature.

\subsection{Selection of curing conditions}

To study the effects of different curing conditions on coating performance, we used the sulfidation resistance test of 2.2.4; the degree of conversion of coating was evaluated by testing the optoelectronic property of lamps before and after sulfuration in different curing conditions.

The curing conditions and results are shown in Tables 6 and 7 , respectively.

Table 6 Curing conditions

\begin{tabular}{llll}
\hline & Factor & & \\
\cline { 2 - 4 } Level & $\begin{array}{l}A \text { temperature/ } \\
{ }^{\circ} \mathrm{C}\end{array}$ & $\begin{array}{l}B \text { relative } \\
\text { humidity } / \%\end{array}$ & $\begin{array}{l}C \text { curing } \\
\text { time } / \mathrm{h}\end{array}$ \\
\hline 1 & 25 & 50 & 6 \\
2 & 80 & 90 & 8 \\
3 & 150 & - & 24 \\
4 & - & - & 72
\end{tabular}

Table 5 Effects of different catalysts on coating performance ${ }^{a}$

\begin{tabular}{|c|c|c|c|c|c|c|}
\hline $\begin{array}{l}\text { Test } \\
\text { no. }\end{array}$ & $\begin{array}{l}\text { Amine } \\
\text { compounds }\end{array}$ & $\begin{array}{l}w \text { (amine } \\
\text { compounds)/\% }\end{array}$ & Solvent & $\begin{array}{l}\text { Coating } \\
\text { thickness/ } \mu \mathrm{m}\end{array}$ & $\begin{array}{l}\text { Coating } \\
\text { quality }\end{array}$ & $\begin{array}{l}\text { Oxygen permeation } \\
\text { flux } / \mathrm{cm}^{3} \mathrm{~m}^{2}, 24 \mathrm{~h} 0.1 \mathrm{MPa}\end{array}$ \\
\hline 1 & I & 1.0 & Dibutyl ether & 16.8 & $\mathrm{~A}, \mathrm{~B}, \mathrm{C}$ & 263.7 \\
\hline 2 & I & 3.0 & Dibutyl ether & 17.4 & $\mathrm{~A}, \mathrm{~B}, \mathrm{C}$ & 206.4 \\
\hline 3 & $\mathrm{I}$ & 5.0 & Dibutyl ether & 17.2 & $\mathrm{~A}, \mathrm{~B}, \mathrm{C}$ & 1.4 \\
\hline 4 & $\mathrm{I}$ & 10.0 & Dibutyl ether & 17.8 & $\mathrm{~A}, \mathrm{~B}, \mathrm{C}$ & 1.4 \\
\hline 5 & II & 5.0 & Dibutyl ether & 18.2 & $\mathrm{~A}, \mathrm{~B}, \mathrm{C}$ & 236.4 \\
\hline 6 & III & 1.0 & Dibutyl ether & Unmeasurable & $\mathrm{D}, \mathrm{E}$ & Unmeasurable \\
\hline 7 & III & 5.0 & Xylene & 17.4 & $\mathrm{~A}, \mathrm{~B}, \mathrm{C}$ & 247.2 \\
\hline 8 & IV & 1.0 & Dibutyl ether & Unmeasurable & $\mathrm{D}, \mathrm{E}$ & Unmeasurable \\
\hline 9 & IV & 5.0 & Xylene & 18.5 & $\mathrm{~A}, \mathrm{~B}, \mathrm{C}$ & 218.6 \\
\hline 10 & $\mathrm{~V}$ & 1.0 & Dibutyl ether & Unmeasurable & $\mathrm{D}, \mathrm{E}$ & Unmeasurable \\
\hline 11 & $\mathrm{~V}$ & 5.0 & Xylene & 18.1 & $\mathrm{~A}, \mathrm{~B}, \mathrm{C}$ & 226.5 \\
\hline
\end{tabular}

${ }^{a}$ Curing conditions: room temperature, relative humidity of $50 \%$, for 24 hours. $\mathrm{A}=$ uniform, $\mathrm{B}=$ continuous, $\mathrm{C}=$ defect-free, $\mathrm{D}=$ uneven, $\mathrm{E}=$ defective. 
Table 7 Lamp optoelectronic properties before and after sulfuration in different curing conditions ${ }^{a}$

\begin{tabular}{|c|c|c|c|c|c|c|}
\hline Curing conditions & Amine compounds & $w$ (amine compounds)/\% & Coating thickness $/ \mu \mathrm{m}$ & $a / 10^{-2} \mathrm{~W}$ & $b / 10^{-2} \mathrm{~W}$ & $c / \%$ \\
\hline$A_{1} B_{1} C_{3}$ & I & 5.0 & 16.8 & 2.126 & 2.124 & 99.91 \\
\hline$A_{1} B_{1} C_{4}$ & I & 5.0 & 17.2 & 2.223 & 2.221 & 99.91 \\
\hline$A_{2} B_{2} C_{1}$ & I & 5.0 & 17.5 & 2.147 & 2.145 & 99.91 \\
\hline$A_{3} B_{2} C_{1}$ & I & 5.0 & 16.6 & 2.235 & 2.233 & 99.91 \\
\hline$A_{1} B_{1} C_{3}$ & II & 5.0 & 16.5 & 2.253 & 1.575 & 69.91 \\
\hline$A_{1} B_{1} C_{3}$ & $\mathrm{~V}$ & 5.0 & 16.3 & 2.237 & 1.481 & 66.20 \\
\hline
\end{tabular}

${ }^{a} A=$ average optical power before sulfuration, $B=$ average optical power after sulfuration, $C=$ average flux maintenance rate after sulfuration.

As can be seen, using tetramethylhexamethylenediamine as a catalyst under the curing conditions in Table 6 gave a luminous flux maintenance of $99.8 \%$ after vulcanization, indicating that this catalyst had excellent sulfidation resistance. At room temperature and a relative humidity of $50 \%$ for 24 hours, the optimal degree of siliceous conversion was obtained. Using extended curing times, this effect remained unchanged; and the siliceous conversion time could be effectively shortened by increasing heating temperature and relative humidity.

Using tetramethylethylenediamine, xylylenediamine, hexamethylenediamine, or trimethylenebis ( $N$-methylpyridine) as catalysts at room temperature and a relative humidity of $50 \%$ for 24 hours, the luminous flux maintenance of the lamps after vulcanization was equal to or less than $75 \%$; the anti-sulfidation properties were not ideal, indicating that these siliceous conversions were not high and did not have high density and high barrier at this curing condition.

\section{Conclusions}

Optically transparent trifluoropropyl phenyl silicone rubber combined the advantages of phenyl silicone rubber and fluorinecontaining silicone rubber and exhibited excellent oil and heat resistance. This rubber overcame the disadvantages of opacity, high gas permeability, and no enduring high temperature and oil of methyl silicone rubber. In summary, low gas permeability coating prevent electronic components, chips, electrodes, medicines, etc. from oxidation and sulfuration by oxygen, hydrogen sulphide, and sulphur vapour and extend their service lives. This coating also realizes low-temperature curing and siliceous transition, which make the application more convenient and extensive, and is expected to be applied in other materials and fields.

\section{Conflicts of interest}

There are no conflicts to declare.

\section{Acknowledgements}

This study was supported by Funds of Applied Science and Technology Research in Guangdong Province, China (2017A070701024,
2017A070702020), and Special Fund Project for Technology Development of Guangdong Province, China (2016B070701023).

\section{References}

1 S. A. Seyedmehdi, H. Zhang and J. Zhu, Prog. Org. Coat., 2016, 90, 291-295.

2 D. Liu, J. Chen and L. Song, Polymer, 2017, 120, 155-163.

3 P. Jha, L. W. Mason and J. D. Way, J. Membr. Sci., 2006, 272, 125-136.

4 D. W. Kang, H. G. Yeo and K. S. Lee, J. Inorg. Organomet. Polym., 2004, 14, 73-84.

5 A. B. Birkefeld, H. Eckert and B. Pfleiderer, Biomaterials, 2004, 25, 4405-4413.

6 Q. G. Gu and Q. L. Zhou, Eur. Polym. J., 1998, 34, 1727-1733.

7 J. Zhang and S. Y. Feng, J. Appl. Polym. Sci., 2003, 89, 34713475.

8 Y. Tang and R. Tsing, Polymer, 1999, 40, 6135-6146.

9 A. Kojima, S. Hoshii and T. Muto, J. Mater. Sci. Lett., 2002, 21, 757-760.

10 M. Gnthner, T. Kraus and A. Dierdorf, J. Eur. Ceram. Soc., 2009, 29, 2061-2068.

11 P. Lutz, D. Andreas and L. Hubert, Chem.-Eur. J., 2007, 13, 8522-8529.

12 B. Frank, D. Ulrich and D. Andreas, Prog. Org. Coat., 2005, 53, 183-190.

13 G. Martin, K. Tobias and K. Walter, Int. J. Appl. Ceram. Technol., 2009, 6, 373-380.

14 O. Funayama, Y. Tashiro and A. Kamo, J. Mater. Sci., 1994, 29, 4883-4888.

15 T. Takahiro, H. Koji and Y. Masuji, Dent. Mater. J., 2011, 30, 170-175.

16 K. Tomoko, T. Eisuke and K. Hiromitsu, J. Sol-Gel Sci. Technol., 2004, 31, 257-261.

17 Z. J. Peng, X. L. Fu and N. Zhu, J. Non-Cryst. Solids, 2009, 355, 2156-2159.

18 M. Matteo, D. Barbara and B. Renzo, J. Cult. Herit., 2008, 9, 143-145.

19 C. Chiaming, Y. Minghsin and C. Hungju, Microelectron. Eng., 2010, 87, 1927-1931. 